\title{
Empreendedor Social: entre a educação formal e não formal
}

\author{
Social Entrepreneur: between formal and non formal education
}

\author{
Lucimar da Silva Itelvino ${ }^{1}$ \\ Priscila Rezende da Costa ${ }^{2}$ \\ Maria da Gloria Marcondes Gohn ${ }^{3}$ \\ Claudio Ramacciotti ${ }^{4}$
}

\begin{abstract}
Resumo
A formação do empreendedor social não está atrelada somente à trajetória de liderança, que representa o exercício pleno do empreendedorismo social. Ela pode, também, ser moldada pelos espaços e contextos de aprendizagem aos quais ele foi submetido ao longo de sua história de vida, além de ser direcionada pelas motivações que teve em promover inovações sociais. A fim de compreender esse processo formativo - que é o objetivo deste artigo - buscou-se reconhecer a ambientação da capacitação desse profissional, seus estímulos e o caminho de liderança social, haja vista serem esses os elementos responsáveis pelo desenvolvimento profissional e social que gera transformações socioambientais. Para tanto, a pesquisa, de caráter qualitativo, contemplou a análise de 59 histórias de vida de empreendedores sociais, publicadas no período de 2005 a 2013, pelo jornal Folha de São Paulo, criador do concurso Prêmio Empreendedor Social no Brasil, em parceria com a Fundação Schwab. Concluiu-se que as atitudes do empreendedor social são construídas e renovadas continuamente, durante a vida, não se tratando, portanto, de uma formação com propósitos de desempenho profissional e acadêmico, mas decorrente de uma atuação cidadã, condizente com a demanda de pertencimento e reconstrução das relações sociais do mundo contemporâneo.
\end{abstract}

Palavras-chave: Empreendedor social. Educação formal. Educação não formal. História de vida.

\begin{abstract}
The formation of the social entrepreneur is not only linked to the leadership trajectory, which represents the full exercise of social entrepreneurship. It can also be shaped by the spaces and contexts of learning to which it has been subjected throughout its life history, in addition to being driven by the motivations it had to promote social innovations. In order to understand this formative process - which is the objective of this article - we sought to recognize the setting of the professional's qualification, its stimuli and the path of social leadership, since these are the elements responsible for the professional and social development that generates transformations socio-environmental. To this end, the qualitative research included the analysis of 59 life histories of social entrepreneurs, published in the period from 2005 to 2013, by the newspaper Folha de São Paulo, creator of the contest Social Entrepreneur Award in Brazil, in partnership with Schwab Foundation. It was concluded that the attitudes of the social entrepreneur are continuously built and renewed, during the life, and are not, therefore, a training for purposes of professional and academic performance, but resulting from a citizen's action, in keeping with the demand for belonging and reconstruction of the social relations of the contemporary world.
\end{abstract}

Keywords: Social entrepreneur. Formal education. Non formal education. Life's history.

Doutora em Educação - Universidade Nove de Julho. Afiliação: Universidade Nove de Julho. Lattes: http://lattes.cnpq.br/4840136912136365 Email: lucimarsilva@uninove.br

2 Doutora em Administração - Universidade de São Paulo. Afiliação: Universidade Nove de Julho. Lattes: http://lattes.cnpq.br/5631049543029993 - Email: priscilarezende@yahoo.com.br

3 Doutora em Ciência Política - Universidade de São Paulo. Afiliação: Universidade Estadual de Campinas. Lattes: http://lattes.cnpq. br/8315862641929394 - Email: mgohn@uol.com.br

4 Doutor em Administração - Fundação Getúlio Vargas. Afiliação: Universidade Nove de Julho. Lattes: http://lattes.cnpq.br/1766416325019362 Email: claudior@uninove.br 


\section{Introdução}

Na educação não formal, a aprendizagem acontece de forma interativa e intencional, pois há um propósito na ação, no ato participativo, de aquisição, transmissão ou troca de saberes; além disso, os seus objetivos não são dados a priori, porque eles se constroem a partir de processos coletivos geradores de capital social (GOHN, 2013; WILLEMS, 2015).

Usa-se o termo "capital" por se tratar de um ativo, e a palavra "social" indica, por sua vez, que esse é um ativo alcançado pelo pertencimento a uma comunidade, por meio da interação e do aprendizado. Quando o conhecimento e as habilidades dos membros de um grupo são utilizados de modo integrado, os resultados são mais satisfatórios, pois decorrem da aprendizagem (WILLEMS, 2015).

O capital social torna o ambiente mais propício às ações empreendedoras e ao desenvolvimento local a partir de inovações sociais partilhadas (BITENCOURT, 2013; ITURRIOZ; ARAGÓN; NARVAIZA, 2015; TONDOLO; TONDOLO). O empreendedorismo social, portanto, é um exemplo prático de educação não formal, uma vez que promove a criação de uma identidade coletiva, com dada comunidade; constrói e reconstrói a concepção de e sobre o mundo; forma o indivíduo para a vida e suas adversidades; contribui para o resgate da valorização de si mesmo e para a aquisição do conhecimento de sua própria prática; constituindo, com isso, o capital social (GOHN, 2013; ITURRIOZ; ARAGÓN; NARVAIZA, 2015).

O ponto central do empreendedorismo é o sentido dado às ações em sociedade, em função do surgimento de novos atores, da criação de valor e do fortalecimento das relações estabelecidas. A ação individual, muito valorizada nessa área, num processo de socialização, assume caráter coletivo. Nesse sentido, os assuntos relativos à sociedade são transformados, por esses profissionais, em oportunidades e negócios; e a experiência adquirida torna-se conhecimento empreendedor, que promove valor social.

Cabe enfatizar que a motivação social é explícita, pois envolve a aplicação e o domínio das competências de liderança, a fim de resolver um problema social (SLOAN; LEGRAND; SIMONS, 2014). Sendo assim, as atividades empreendedoras geram valor social e, se há também valor econômico, ele deve ser visto como um meio necessário para assegurar a viabilidade financeira do empreendimento social (MAIR; MARTI, 2006). Para Dacin e Dacin (2010), Dacin e Tracey (2011), Muñoz e Kibler (2015) e Phillips et al. (2015), é preciso um equilíbrio entre esses valores, uma vez que o valor econômico é crucial para a sustentabilidade dos empreendimentos e para a criação inovadora de valor social.

Na perspectiva sociológica (e, consequentemente, na trajetória de vida), destaca-se a relação entre o comportamento de liderança e os valores dos empreendedores. Navarro, Climent e Palacio (2011) sustentam, a esse respeito, que o apego emocional às relações de trabalho e à satisfação profissional, assim como ao sentimento de pertencimento, são mais significativos para os empreendedores sociais, apesar de os salários serem menores. Por conta disso, eles tendem a ficar mais tempo nas organizações em que atuam, porque a atividade desenvolvida está diretamente ligada ao estilo de vida daqueles sujeitos, não representando somente uma opção de carreira.

Apesar de as discussões sobre a formação formal e não formal dos empreendedores sociais, com base na trajetória de liderança, nos espaços e contextos de aprendizagem e nas motivações que propiciaram as inovações sociais (DAVID, 2004; MINUZZI; BELINAZO; LEZANA, 2005; NAVARRO; CLIMENT; PALACIO, 2011; YUKL; GORDON; TABER, 2002), seremoportunas, não há, na literatura vigente, estudos que relacionam esses aspectos. Tal lacuna remete à problemática de pesquisa que este trabalho pretende responder: Como ocorre o processo de formação do empreendedor social?

Este estudo é relevante devido à importância do empreendedorismo social enquanto temática de política pública, pois ele tem sido pauta recorrente em debates, em diferentes estratos da sociedade, como método de melhoria da qualidade de vida das pessoas e de geração de desenvolvimento sustentável. Para a área acadêmica, este trabalho de pesquisa preencheu uma lacuna no processo de formação de futuros empreendedores sociais, indicando os elementos didáticos a serem desenvolvidos pelas esferas educacionais e organizacionais, a fim de fomentar novos empreendimentos desse tipo, dado o fato de que as iniciativas governamentais, muitas vezes, não são capazes de suprir todas as demandas, sobretudo dos mais carentes. Além disso, o assunto é relevante à promoção das empresas do Terceiro Setor e à geração 
de inovações sociais (FRIEDLAENDER, 2004; MURPHY; LIÃO; WELSCH, 2006), uma vez que, à medida que o empreendedor social se desenvolve, ele determina os valores, a rede de parceiros e os procedimentos técnicos e interpessoais adotados nos projetos sociais (FARFUS; ROCHA, 2007; PARENTE et al., 2011; SOUSA et al., 2013).

\section{Empreendedorismo social}

Para Melo Neto e Fróes (2002, p. 49), "no âmbito do empreendedorismo social, a inovação é maior e melhor, porque desenvolve a projeção de mudanças significativas na sociedade onde está implementada". Nessa perspectiva, o empreendedor social adquire a capacidade de gerar inovação ao identificar diferentes maneiras para modificar as condições de vida dos excluídos da sociedade. Não se trata de mero trabalho filantrópico, mas de um processo de evolução humanitária (MELLO; SANT'ANNA, 2016; ONOZATO; TEIXEIRA, 2011).

Para Dornelas (2007), o cerne no empreendedorismo social é a relação indissociável entre a realização pessoal /profissional e a possibilidade de oportunizar uma vivência mais apropriada e justa ao outro. Para tanto, busca-se criar organizações que preencham as lacunas sociais deixadas pelo Estado. Caso o processo gere retorno financeiro, mesmo não sendo este um dos objetivos finais, a aquisição desses novos recursos pode auxiliar essas organizações no compartilhamento da intenção de capacitar o cidadão.

Melo Neto e Fróes (2002) complementam a afirmação acima, explicando que o empreendedor social olha para o coletivo, fala na primeira pessoa do plural (nós) e indigna-se com a exclusão social, a pobreza e a miséria. Isto indica que o risco de vida do outro, muitas vezes, é o que motiva e impulsiona suas ações. No empreendedorismo social, a inovação de produtos e serviços é consequência da busca de metodologias para solucionar os problemas da sociedade, garantindo, com isso, dignidade ao ser humano. A medida de sucesso para esse profissional é, então, o impacto causado socialmente, haja vista a sua condição de agente de mudanças; devendo-se, igualmente, considerar que as ideias e metodologias inovadoras criadas são passíveis de divulgação, aplicação e multiplicação em outros grupos que estão em situação semelhante. A satisfação profissional desse cidadão está, então, vinculada à melhoria da qualidade de vida, ao progresso material, espiritual e pessoal dos beneficiados com a solução proposta, obtidos, especialmente, por conta do envolvimento dos membros da comunidade, por meio da participação, integração e desenvolvimento coletivo. Com suas ações, o empreendedor social espera retirar a pessoa da situação de risco, capacitando-a e oferecendo a ela oportunidades de reinserção social. A educação e a criação de novos espaços de experiência de vida participativa, bem como o referencial ético e a figura de liderança - dada a capacidade do empreendedor social de mobilização, pois ele incentiva a subordinação do aspecto econômico ao ser humano -, são fatores essenciais nesse processo. O desejo de transformação da realidade concretiza-se, portanto, quando o empreendedor assume uma atitude de inconformismo e crítica diante das injustiças observadas.

Em suma, para Melo Neto e Fróes (2002), a transformação da realidade está centrada no paradigma que vincula ao empreendedorismo social a (re)construção da participação e reflexão, nas comunidades; a implementação de soluções inovadoras para a inserção social; o exercício da cidadania; a justiça social; a geração de renda; e a produtividade das parcerias entre os diferentes setores da sociedade.

O empreendedorismo social está, sobretudo, associado à problemática do desenvolvimento local, até porque a competitividade das empresas envolve o entorno produtivo e institucional do qual elas fazem parte. Seu processo, então, cria soluções inovadoras para problemas sociais imediatos, diante dos quais mobiliza ideias, capacidades, recursos e arranjos necessários à geração de transformações sociais sustentáveis (ALVORD; BROWN; LETTS, 2004).

Diante desse contexto, a intenção do empreendedor social é maximizar o valor social a partir de ações inovadoras (AUSTIN; STEVENSON; WEI-SKILLERN, 2006; CERTO; MILLER, 2008). Por isso, a Escola de Inovação Social tem como unidade de análise central o perfil do empreendedor social, definido como aquele que responde às necessidades sociais de forma inovadora (HOOGENDOORN; PENNINGS; THURIK, 2010; PHILLIPS et al., 2015). Para Dees e Economy (2001), ele é, por excelência, um inovador, 
pois assume a motivação de atacar as causas dos problemas e produzir mudanças fundamentais na vida das pessoas, uma vez que sua missão é criar e sustentar o valor social. Parente et al. (2011), por sua vez, dizem que o estímulo desse profissional está no desenvolvimento e/ou combinação de produtos/serviços de caráter inovador, com a finalidade de promover modificações na sociedade, capazes de serem replicadas e ampliadas em outros contextos e comunidades.

De forma a complementar o arcabouço de reflexões teóricas, Friedlaender (2004) aponta a dedicação cada vez maior dos comportamentalistas ao estudo da liderança dos empreendedores sociais a partir do meio ambiente. Corroborando essa visão, Bandura (2002) e Murphy, Lião e Welsch (2006) afirmam que as ações de liderança do empreendedor social são determinadas pela interação de variáveis comportamentais, cognitivas e ambientais/situacionais.

Segundo Abu-Saifan (2012), o empreendedor social adota um conjunto de comportamentos empresariais de liderança, a fim de entregar valor social à sociedade, a partir de uma entidade empreendedora, financeiramente independente, autossuficiente e sustentável. Já na visão de Oliveira (2004), sua liderança empreendedora, exercida em contextos sociais, significa que ele é inconformado e indignado com a injustiça e desigualdade, além de engajado, comprometido, leal, ético, transparente e apaixonado pelo que faz. Ademais, tem-se a afirmação de Austin, Stevenson e Wei-Skillern (2006), que destacam o "saber ser" e o "saber fazer" para "saber agir", estando esse profissional sempre atento ao ambiente e aos próprios valores.

Em relação ao contexto coletivo, David (2004) diz que o empreendedor social atua como líder nas ações relativas ao bem comum, interferindo diretamente em um grupo/organização por intermédio de suas propostas, provocativas de mudanças nas relações sociais. Nesse sentido, Yukl, Gordon e Taber (2002) desenvolveram uma proposta de estruturação para os comportamentos de liderança, envolvendo as seguintes etapas: (a) planejamento de atividades de curto prazo, explicitação dos objetivos das tarefas e as expectativas sobre cada um deles, bem como monitoramento de toda a operação; (b) suporte, encorajamento, reconhecimento das realizações e contribuições, consulta para decisão e cessão de empowerment para a solução de problemas; e (c) supervisão do ambiente externo, proposta de estratégias inovadoras ou novas visões, e estímulo do pensamento inovador. De acordo com Jiao (2011), é assim estabelecida a relevância da liderança empreendedora, durante a criação e o desenvolvimento de ações sociais, visto que o empreendedor exerce um papel decisivo no delineamento da cultura dos empreendimentos e projetos sociais, pois insere nele seus valores e visão de mundo.

Vale considerar, também, que esse profissional é parte de uma sociedade e, dessa forma, partilha com outros indivíduos uma conjuntura de experiências capazes de influenciar sua liderança e ações. Ele se depara com exigências que ultrapassam as fronteiras organizacionais, transitam por decisões governamentais, tendências econômicas e pelas necessidades das comunidades locais. Assim, as organizações sociais demandam um líder empreendedor apto a alinhar o empreendimento às necessidades e oportunidades sociais do ambiente (MINUZZI; BELINAZO; LEZANA, 2005).

\section{Espaços e contextos de formação social}

Os processos de formação são construídos e reconstruídos a partir dos conhecimentos acumulados pela educação, em diferentes espaços sociais, que definem "a forma que se incorpora tanto os 'saberes' formais e cotidianos quanto os valores e crenças com os quais se tem contato, que, por sua vez, definem as possibilidades de ação sobre o mundo" (OLIVEIRA, 2008). Ressalta-se que os saberes cotidianos são internalizados, ao passo que as relações do educando se estabelecem em espaços sociais não formais (GOHN, 2006; JACOBUCCI, 2008).

Pode-se inferir, portanto, a existência de diferentes "espaços" (PETITAT apud GATTI JÚNIOR; INÁCIO FILHO, 2005) ou "espaços de formação" (GRAMSCI apud NOSELLA; AZEVEDO, 2012, p.25) sociais e educacionais, construídos, no início, de maneira espontânea e não formal, para suprir as necessidades humanas e, processualmente, num momento posterior, após determinado estágio, passam a ser formalizados e institucionalizados. 
Considerando que os ambientes sociais destinados ao ensino e à aprendizagem resultam de "um processo de crescimento e desenvolvimento de uma pessoa em sua totalidade, abarcando minimamente quatro grandes áreas: a do conhecimento, a do afetivo-emocional, a de habilidades e as atitudes ou valores" (MASSETO, 2003, p. 37), conclui-se que a formação pode vir a ser realizada em diferentes espaços e contextos.

Assim, o espaço da educação não formal corresponde "àquele em que os indivíduos aprendem durante seu processo de socialização - na família, bairro, clube, amigos (...) carregado de valores e culturas próprias, de pertencimento e sentimentos herdados" (GOHN, 2006, p. 28). Essa educação é, então, espontânea, sendo que muitos dos valores internalizados resultam das relações sociais herdadas por parentesco, compartilhadas por afinidade. Nesse sentido, reconhece-se a família como um importante espaço formativo da educação não formal, visto que, na "privacidade, prevalecem códigos culturais informais, diferentes daqueles que vigoram no domínio público, regido por preceitos formais e impessoais" (ROMANELLI, 1995, p. 451). Tais espaços "localizam-se em territórios que acompanham as trajetórias de vida dos grupos e indivíduos, fora das escolas, em locais informais, locais onde há processos interativos intencionais" (GOHN, 2006, p. 29).

A educação não formal designa, por conseguinte, um processo de várias dimensões, como: a aprendizagem política dos direitos dos indivíduos enquanto cidadãos; a capacidade para o trabalho, por meio do desenvolvimento de habilidades e/ou potencialidades; a aquisição de conhecimentos e práticas que capacitam os cidadãos a se organizarem, a partir de objetivos comunitários; a apreensão de conteúdos possibilitadores de uma leitura mais ampla do mundo, considerando o que se passa ao redor do indivíduo; a educação desenvolvida na e pela mídia, em especial, a eletrônica (GOHN, 2006, p. 29). Seus movimentos, organizados pela sociedade civil, muitos deles resultantes de engajamentos políticos e sociais, dedicamse à ação social em espaços públicos. Essa "comunicação" de histórias e expectativas individuais são transformadas, com isso, em processos educativos coletivos.

Assim, se a educação formal "é aquela desenvolvida nas escolas, com conteúdos demarcados" (GOHN, 2006, p. 28), nos espaços da educação não formal, mesmo não havendo intencionalidade, há a transformação da vida dos beneficiários dos projetos sociais, pois nele se pressupõem construções coletivas, constituídas pelos problemas do cotidiano (que são meios de se identificar a necessidade dos indivíduos e grupos) e pelo processo de aprendizagem, definido, de acordo com o contexto, como "os conteúdos emergem a partir dos temas que se colocam como necessidades, carências, desafios, obstáculos ou ações empreendedoras a serem realizados" (GOHN, 2006, p. 31). Destaca-se, também, o fato de que tal ambientação deve respeitar as diferenças, reconhecer a existência do outro e a necessidade de compartilhamento de espaço coletivo, não podendo, de modo algum, ser excludente, haja vista que a integração das competências, habilidades, conhecimentos e valores, oriundos e adquiridos tanto nos espaços de educação formal quanto naqueles não formais, possibilita, pois, ao sujeito, a transposição de um estado de exclusão para a cidadania.

\section{Metodologia de pesquisa}

Adotou-se uma abordagem qualitativa para a pesquisa, pois ela oferece uma compreensão detalhada dos significados e das características situacionais, apresentados pelos objetos da investigação (RICHARDSON, 2004); além de imprimir significado para os fenômenos humanos, por meio da interpretação e da compreensão (LIMA, 2008).

Com o objetivo de compreender esses significados no processo de formação, foram analisadas 59 narrativas de histórias de vida de empreendedores sociais, considerados referência na geração de inovações de impacto na sociedade brasileira. Salienta-se que as fontes dessas narrativas são secundárias, uma vez que elas se pautaram no Prêmio Empreendedor Social, realizado pelo jornal Folha de São Paulo e pela Fundação Schwab no período de 2005 a 2013.

A análise de histórias de vida, segundo Alberti (2004), é um método que permite ao pesquisador e/ou à pesquisa: extrair informações e conhecimentos detidos pelos indivíduos; reconstruir fatos que não estão registrados em outros tipos de fontes; identificar como as pessoas efetuam e elaboram suas experiências; relacionar situações de aprendizagem e decisões; entender como o passado é experimentado e suas ações 
cotidianas interpretadas, individual ou coletivamente; e delinear a trajetória existencial, com vista a um objeto de estudo (no caso deste trabalho, o processo de formação do empreendedor social).

Para a análise de tais histórias, foram consideradas as narrativas autobiográficas dos empreendedores sociais, apresentadas ao longo do concurso "Empreendedor Social", pois elas abarcam o relato de experiências profissionais e de vida. Embora constituam uma fonte secundária de evidência, são autobiográficas, isto é, constituem um material precioso e atemporal, uma vez que revelam conhecimento tácito, importante para ser compreendido, e refletem igualmente a não separação entre pensamento e ação (GALVÃO, 2005).

Adam (2008) divide em dois tipos os fatos a serem expostos em narrativas: eventos e ações. As ações caracterizam-se pela presença de um agente, que provoca ou tenta evitar uma mudança no estado das coisas. Os eventos, por sua vez, ocorrem sob o efeito de causas, sem qualquer intervenção intencional. Assim, toda narrativa desenvolve uma trama, que possui cinco momentos possibilitadores da compreensão do que é narrado: 1) situação inicial: o ponto de partida da narração; 2) nó desencadeador: algo que ocorre e é responsável pelo desenvolvimento da narrativa; 3) reação ou avaliação: a atitude do agente da narrativa frente ao nó desencadeador; 4) desenlace: a resolução; e 5) situação final.

Com base nos elementos acima indicados, buscou-se analisar as fases e eventos marcantes das histórias de vida dos empreendedores sociais, bem como levantar as expressões e atitudes determinantes de sua atuação social. Para tanto, adotou-se a técnica de análise de conteúdo, que é uma oportunidade para ler e interpretar documentos, garantindo o aspecto qualitativo do estudo (OLABUENAGA; ISPIZUA, 1989). Ela permite, também, o aprofundamento no mundo dos significados das ações e das relações humanas, além de ir além do que se tem como resultado claro e manifesto, tornando possível, por inferência, captar até mesmo aquilo que o autor deixou subentendido (FREITAS; JANISSEK, 2000).

Em ambas as etapas, utilizou-se o software ATLAS, sexta versão, pois ele organiza e a recupera informações relacionadas à ideia ou ao conceito subjacente às categorias de análise, criadas pelo pesquisador, a partir da revisão da literatura, o que é importante para estruturar e validar empiricamente o processo de retorno aos dados qualitativos (LEE; ESTERHUIZEN, 2000).

As categorias de análise que respaldaram a organização e cruzamento dos dados, no software ATLAS, são: espaços e contextos de aprendizagem; motivações do empreendedorismo social; e trajetória de liderança social (DAVID, 2004; OLIVEIRA, 2004; YUKL; GORDON, TABER; 2002). Considerando-se os códigos de análise: ampliação da intervenção social; atuação profissional; autossuperação; colaboração; curiosidade; desenvolvimento de ações inovadoras para a intervenção social e ambiental; determinação; enfrentamento; estabelecimento de espaços para debate; foco; formação acadêmica; formação cultural; formalização; gratidão; independência; indignação; inquietação; justiça; liderança social; obtenção de fonte de renda; otimismo; parcerias; preocupação com a realidade social; questionamentos; referência familiar e paterna; transformação; e voluntariado (MACÊDO; BOAVA, 2008; MINUZZI; BELINAZO, LEZANA, 2005; NAVARRO; CLIMENT, PALACIO, 2011).

\section{Resultados}

\subsection{Caracterização do Terceiro Setor no Brasil}

No contexto brasileiro do Terceiro Setor, estima-se que o número de entidades seja superior a 556.846 e, no que tange à estrutura ocupacional, observa-se que a maioria atua sem remuneração. Há, todavia, a presença expressiva de pessoas atuantes como profissionais e que são remuneradas nessas entidades; além da ocorrência de organizações com grande concentração de pessoal ocupado.

De acordo com os dados mais recentes, divulgados pelo Instituto Brasileiro de Geografia e Estatística (IBGE, 2014), existem, no Brasil, 676 unidades locais sem fins lucrativos, com mais de 500 pessoas ocupadas. É possível, portanto, perceber tendências de profissionalização nesse setor de atividade econômica. Isto indica que, do reconhecimento e da formalização do Terceiro Setor, surge espaço para atuação de quem, até então, agia de forma filantrópica ou assistencialista; e, ao mesmo tempo, a necessidade de delinear a construção da identidade desse profissional, agora denominado como empreendedor social (Tabela 1). 
Tabela 1. Unidades locais das entidades sem fins lucrativos, segundo faixas de pessoal ocupado em 2010.

\begin{tabular}{cc}
\hline Faixas de pessoal ocupado & Número de unidades locais das entidades sem fins lucrativos \\
\hline Total & 556846 \\
Sem pessoal ocupado & 336943 \\
1 a 2 pessoas & 99005 \\
3 a 4 pessoas & 34499 \\
5 a 9 pessoas & 49778 \\
10 a 49 pessoas & 28260 \\
50 a 99 pessoas & 4250 \\
100 a 499 pessoas & 3435 \\
500 ou mais pessoas & 676 \\
\hline
\end{tabular}

Fonte: IBGE (2014).

\subsection{Caracterização dos Vencedores e Finalistas do Prêmio Empreendedor Social}

Sobre a caracterização dos 59 vencedores e finalistas do Prêmio Empreendedor Social, realizado pelo jornal Folha de São Paulo e pela Fundação Schwab, no período de 2005 a 2013, computa-se a ocorrência de oito indicações a finalistas, em 2005; nove, em 2006 e 2009; seis, em 2007, 2008, 2010 e 2011; cinco, em 2012; e quatro, em 2013.

Em relação ao gênero dos empreendedores sociais analisados, os números absolutos apresentam 30 mulheres e 29 homens, o que, em números percentuais, equivale apenas a 3,33\% da supremacia feminina. Isto demonstra que o empreendedorismo social é realizado de forma equivalente por ambos os sexos.

Ao observar a área de atuação das organizações sociais, nota-se a predominância de empreendimentos vinculados a atividades de Desenvolvimento e Defesa de Direitos, representados por 19 instituições participantes do Prêmio, ou 33,34\% do total; seguidas das áreas da Saúde, com 12 organizações; Cultura e recreação e Saúde, ambas com 9 organizações; e apenas 2 vinculadas ao Meio Ambiente. É importante destacar que foram 57 participantes e 59 finalistas (empreendedores sociais), porque, no ano de 2009, uma mesma organização premiou dois finalistas.

Analisando-se o perfil educacional formal dos empreendedores sociais, apenas 8 empreendedores não possuem formação universitária; e 51 são graduados em: Medicina (6), Psicologia (6), História (5), Administração (4), Educação (4), Arquitetura (3), Biologia (3), Direito (2), Agronomia (2), Economia (2), Engenharia (2), Música (2), Pedagogia (2), Sociologia (2), Odontologia (2), Design (1), Enfermagem (1), Filosofia (1), Física (1), Publicidade (1).

$\mathrm{Na}$ comparação das organizações sociais em relação à educação formal dos empreendedores e a área do conhecimento, das 9 organizações sociais relativas à Saúde, 8 são lideradas por profissionais graduados em Ciências da Saúde, indicando que formação e vocação são dimensões relevantes à prática do empreendedorismo social. Na área de Desenvolvimento e Defesa de Direitos, observou-se também semelhante aderência, pois, de 20 organizações, 13 são lideradas por profissionais graduados em Ciências Sociais e Humanas.

\subsection{Análise em Profundidade da Narrativa de História de Vida do Empreendedor Fábio Bibancos Rosa (FBR)}

Com o objetivo de compreender os significados do processo de formação do empreendedor social, analisouse em profundidade a narrativa da história de vida de um dos profissionais considerados uma referência na geração de inovações sociais de impacto, no Brasil, segundo o Prêmio Empreendedor Social: Fábio Bibancos de Rosa.

Ainda no colégio, o menino se avizinha de uma das maiores favelas do país - a de Heliópolis: "Estudei em colégio jesuíta e uma hora precisava escolher entre esporte e trabalho social, detestava ficar com a turma 
dos atletas, em meio a toda aquela competitividade, então entrei para a alternativa, que tocava violão e ia para a favela", relata Fábio. Desde então, o menino tomou gosto pela ação social (Figura 1, Fase 2, Evento 1).

Nascido no Ipiranga, zona sul de São Paulo, para conciliar a vontade de ajudar os outros à habilidade manual, ele decidiu ser dentista (Figura 1, Fase 1, Evento 2). Em tempos de abertura política, descobriu a força de lutar pelo que considera justo, como mais democracia na universidade: "Na faculdade a gente era obrigado a fazer aquilo e não tinha muito respaldo científico para discutir. Fui atrás de aprender para melhorar e poder dar informação para que as pessoas pudessem decidir o que é melhor para si, em vez de ficarem totalmente à mercê de um diagnóstico", diz Fábio (Figura 1, Fase 3, Evento 3).

Uma das disciplinas cursadas tratava do atendimento às comunidades carentes. Segundo ele: "Foi horrível, catastrófico. A gente extraía dente, e o cara cuspia no balde. Não era daquela maneira que eu queria ajudar" (Figura 1, Fase 3, Evento 4). "Todos merecem tratamento, mas não em qualquer lugar, quero que os dentistas atendam em seus consultórios, onde tenham os melhores equipamentos e seja oferecida qualidade máxima".

Depois de formado, ele retomou as ações sociais, idealizando o projeto "Adotei um Sorriso", da Abrinq (Associação de Fabricantes de Brinquedos) (Figura 1, Fase 3, Evento 5), o que o levou a perceber que um dentista tinha em mãos um instrumento decisivo para transformar a realidade circundante: "Nós somos profissionais da elite, por nossas cadeiras passa gente muito importante: políticos, empresários, jornalistas. Temos um enorme poder de articulação dentro do consultório, com pacientes fidelizados, já que alguns tratamentos são demorados. Precisamos, então, saber articular o que cada um pode fazer para ajudar". Perfeccionista e determinado, ele criou a "Turma do Bem" que, além de 650 dentistas, reúne 400 voluntários, que trocam correspondências com crianças moradoras de abrigos e vão às escolas públicas (para aplicar um questionário, chamado de índice de prioridade, indicativo de quem mais precisa de tratamento). Para ele, "o foco não é a boca, mas o bem-estar do indivíduo" (Figura 1, Fase 3, Evento 6). Assim, ele cuida do que o sistema público não consegue.

Nota-se, portanto, na história de vida do empreendedor social Fábio que, além da educação formal em Odontologia, a educação não formal foi igualmente marcante, pois houve processos de aprendizagem interativos e intencionais, isto é, ocorreu um propósito na ação, no ato de participar, aprender e transmitir ou trocar saberes. Além disso, os seus objetivos não surgiram a priori, mas se construíram a partir do processo coletivo, gerador de "capital social", conforme destacam Gohn (2006) e Willems (2015).

Seu amigo Marco Ricca, ator, foi levando ao seu consultório alguns colegas de profissão. O "boca a boca" cresceu tanto que Fábio ganhou o apelido de "dentista das estrelas". Hoje, professor, autor de livros e mediador de um "vídeochat", ele aposta no conhecimento para melhorar a vida das crianças atendidas.

Fábio está sempre selecionando os profissionais perfeitos para o projeto e ensina coordenadores regionais a replicar sua estratégia (Figura 1, Fase 3, Evento 7). De colega em colega, já houve tratamento a 1.150 crianças e adolescentes, em 150 cidades do país. "É difícil ser o chefão. Eu gosto de dividir", menciona Fábio. Todos são atendidos até os 18 anos, em consultórios particulares (Figura 1, Fase 3, Evento 8).

Diante desse contexto, percebe-se que os empreendedores sociais são inovadores por excelência, motivados a transformar a sociedade, sendo agentes dessa mudança e adotando a missão de criar e sustentar o valor social (DEES et al., 1998; MUÑOZ; KIBLER, 2015; PHILLIPS et al., 2015). Nesse sentido, as práticas inovadoras de atuação dos empreendimentos sociais precisam ser compartilhadas por todos os atores envolvidos, o que demanda empreendedores sociais com habilidades relacionais cada vez mais desenvolvidas (SOUSA et al., 2013).

Na Figura 1, resultante do comando de geração de Network do software ATLAS.ti, são apresentadas graficamente as categorias de análise da história de vida do empreendedor social analisado. As redes estabelecidas evidenciam as fases (code family), os eventos (code) e os memorandos (memos) (caracterizaram os eventos). Além disso, há setas que representam a conexão entre as fases e os eventos que as compõem, e a relação de sequência entre eventos.

A história de vida de Fábio Bibancos de Rosa (FBR), vencedor do concurso Prêmio Empreendedor Social em 2006, a partir do comando de geração de network do ATLAS.ti, foi demarcada em três fases, com oito eventos. Na primeira fase, verificou-se um evento determinante dos espaços e contextos de aprendizagem do empreendedor social, incluindo a "decisão de se tornar dentista para conciliar a habilidade manual à vontade de 
ajudar os outros" (E2). Na segunda fase, há o evento indicativo das suas motivações para o empreendedorismo social, a "sensibilização pelas condições das comunidades carentes, dada a proximidade vivenciada na infância, despertando interesse pela ação social" (E1). Por fim, a terceira fase é marcada pelos eventos que representativos da trajetória de liderança social de Fábio, incluindo: "vivência democrática, na faculdade, e o despertar de forças para lutar por justiça" (E3); "experimentação da ação social, na universidade, que gerou inquietação pela busca de melhorias" (E4); "transformação da realidade circundante e idealização do projeto 'Adote um Sorriso', em parceria com a ABRINQ" (E5); "criação da 'Turma do Bem', uma rede de voluntários que oferece tratamento dentário e troca correspondência com crianças de abrigos" (E6); "treinamento de coordenadores regionais para replicação das estratégias e dos projetos" (E7); "replicação e continuidade dos projetos de atendimento e acompanhamento de adolescentes e crianças até os 18 anos, em consultórios particulares" (E8).

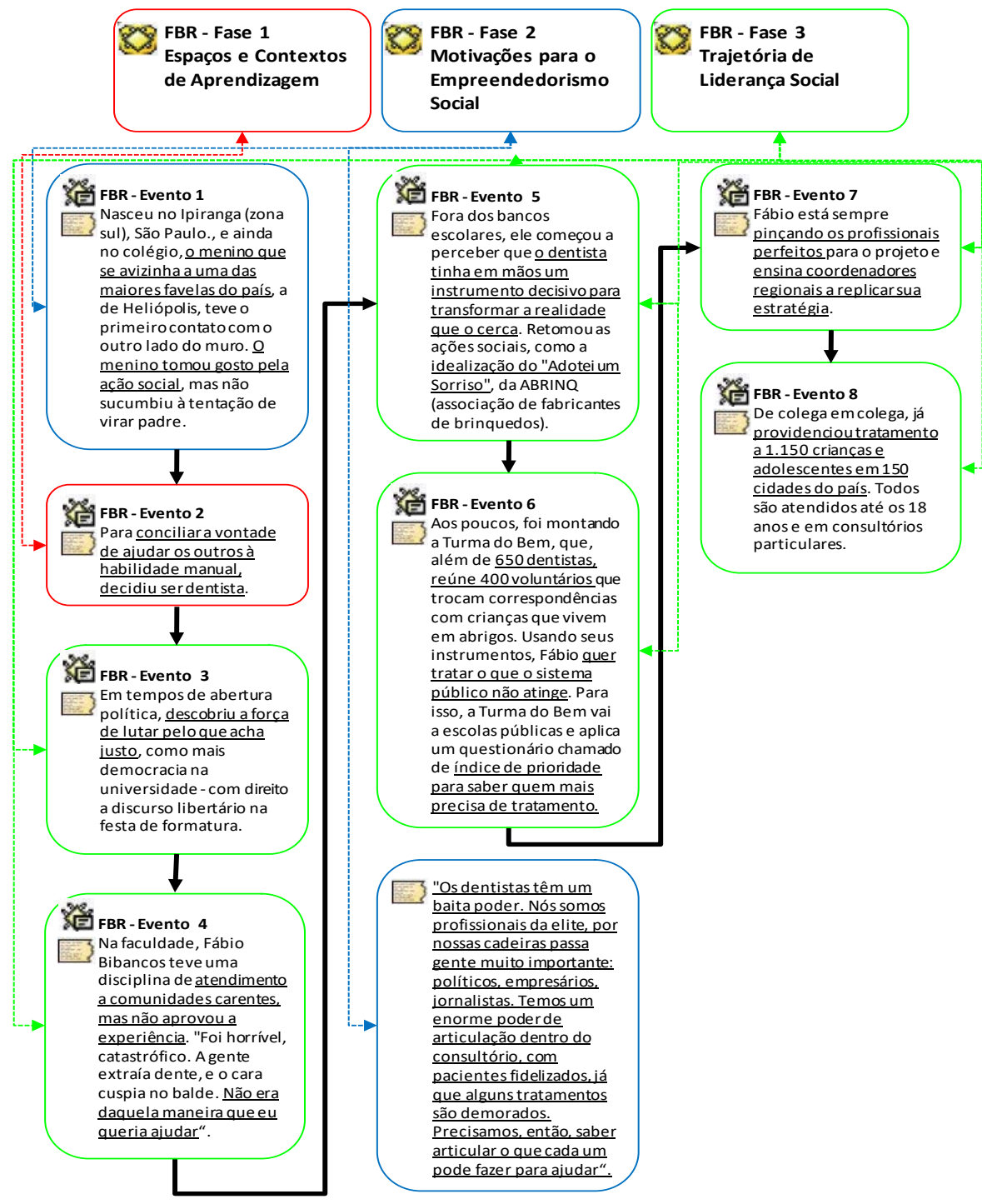

Legenda: FBR (Fábio Bibancos de Rosa); Fases (code family ); 谄 Eventos (code);
Impacto / Memorandos (memos), Frases de
eventos que as compõem; $\rightarrow$ as setas exprimem uma relação de sequência entre os eventos.

Figura 1. Representação gráfica da história de vida do empreendedor social Fábio Bibancos de Rosa (FBR). Fonte: Dados da pesquisa (2016).

\subsection{Análise Agregada das Narrativas de História de Vida dos Empreendedores Sociais}

Com o objetivo de compreender de forma agregada os significados do processo de formação do empreendedor social, foi realizado um cruzamento intracaso, de forma a ampliar a inferência dos achados da pesquisa. Para tanto, foram adotados os comandos da análise cruzada, do ATLAS.ti: "code cooccurrence 
table" e "cluster quotations before calculating co-occurrence", que viabilizaram a interpretação e a classificação das expressões e atitudes relevantes à formação dos empreendedores sociais, vencedores e finalistas (59 histórias de vida).

O Quadro 1 proporciona a visualização (áreas acinzentadas) das expressões e atitudes presentes na formação dos indivíduos, enquanto empreendedores sociais, considerando as dimensões de incidência alta (áreas com cinza escuro), média (áreas com cinza médio) e baixa (áreas com cinza claro).

Sua interpretação possibilitou as seguintes reflexões propositivas sobre a formação do empreendedor social e suas categorias influenciadoras:

(1) Espaços e contextos de aprendizagem - espaços coletivos, formais e/ou informais, onde o indivíduo aprende pela participação em contextos acadêmicos, profissionais e/ou cotidianos, visando à socialização e ao compartilhamento de conhecimentos e experiências. Entre as atitudes relevantes a essa categoria, destacam-se: (a) buscar a autossuperação física, intelectual ou social; (b) estabelecer referência familiar, paterna ou de outra natureza, como exemplo de cidadania e ética; (c) firmar parcerias para geração de aprendizado coletivo; (d) exercer o voluntariado para aprender participando.

(2) Motivação para o empreendedorismo social - criar e maximizar o valor social, por meio de ações inovadoras, com potencial de replicação. Entre as atitudes motivacionais ressaltadas nessa categoria, estão: (a) sentir gratidão em relação à vocação de empreender socialmente; (b) atribuir determinação para concretizar as ações socais; (c) ter otimismo frente aos espaços e contextos da futura intervenção; (d) converter a indignação perante as desigualdades sociais em ações de intervenção efetivas; (e) canalizar a inquietação social na busca de produtos, processos ou métodos inovadores, capazes de ampliar as intervenções sociais; (f) traduzir, por meio de ações, a preocupação contínua com a realidade social.

(3) Trajetória de liderança social - conjunto de ações relativas ao bem comum, que afetaram diretamente um grupo ou organização, por meio de valores e projetos, provocando e inspirando novas mudanças nas relações sociais. Destacam-se as seguintes atitudes relevantes nessa categoria: (a) formalizar ações e projetos de intervenção em organizações sociais; (b) estabelecer justiça a partir de ações e projetos sociais; (c) gerar permanente transformação social, a fim de promover a autonomia dos indivíduos; (d) desenvolver continuamente ações inovadoras de intervenção social e ambiental; (e) ampliar, de forma contínua, a intervenção social para outros contextos e localidades.

Quadro 1. Expressões e Atitudes na Formação dos Indivíduos: Categorias e Sequência de Eventos

\begin{tabular}{|c|c|c|c|c|}
\hline \multicolumn{2}{|c|}{$\begin{array}{l}\text { Categorias de } \\
\text { análise }\end{array}$} & $\begin{array}{l}\text { Espaços e contextos de } \\
\text { aprendizagem }\end{array}$ & $\begin{array}{l}\text { Motivações para o empreendedorismo } \\
\text { social }\end{array}$ & Trajetória de liderança social \\
\hline \multirow{24}{*}{$\begin{array}{l}\text { Sequência } \\
\text { temporal } \\
\text { de eventos } \\
\text { da trajetória } \\
\text { de vida }\end{array}$} & E1 & Enfrentamento & & \\
\hline & \begin{tabular}{|l} 
E2 \\
\end{tabular} & Autossuperação & & \\
\hline & E3 & Referência familiar/paterna & & \\
\hline & E4 & & Gratidão & \\
\hline & E5 & & Determinação & \\
\hline & \begin{tabular}{|l} 
E6 \\
\end{tabular} & Foco & & \\
\hline & E7 & Curiosidade & & \\
\hline & \begin{tabular}{|l} 
E 8 \\
\end{tabular} & & Otimismo & \\
\hline & \begin{tabular}{|l} 
Le \\
\end{tabular} & Formação acadêmica & & \\
\hline & E10 & Atuação profissional & & \\
\hline & E11 & Formação cultural & & \\
\hline & E12 & Parcerias & & \\
\hline & \begin{tabular}{|l} 
E13 \\
\end{tabular} & Voluntariado & & \\
\hline & E14 & & Indignação & \\
\hline & E15 & & Inquietação & \\
\hline & E16 & & Questionamentos & \\
\hline & E17 & & Preocupação com a realidade social & \\
\hline & E18 & Referência familiar/paterna & & \\
\hline & E19 & & Gratidão & \\
\hline & E20 & & Determinação & \\
\hline & E21 & & Otimismo & \\
\hline & E22 & & Independência & \\
\hline & E23 & Parcerias & & \\
\hline & E24 & & Obtenção de fonte de renda & \\
\hline
\end{tabular}


Quadro 1. Expressões e Atitudes na Formação dos Indivíduos: Categorias e Sequência de Eventos (Cont.)

\begin{tabular}{|c|c|c|c|}
\hline E25 & & Indignação & \\
\hline E26 & & Inquietação & \\
\hline E27 & Autossuperação & & \\
\hline E28 & & Preocupação com a realidade social & \\
\hline E29 & & Determinação & Estabelecimento de espacos para \\
\hline E30 & & & debate \\
\hline E31 & & & Formalização \\
\hline E32 & & & Justiça \\
\hline E33 & & & Transformação \\
\hline E34 & Voluntariado & & \\
\hline E35 & & & Colaboração \\
\hline E36 & & & $\begin{array}{l}\text { Desenvolvimento de ações } \\
\text { inovadoras para a intervenção social/ } \\
\text { ambiental }\end{array}$ \\
\hline E37 & & & Liderança social \\
\hline E38 & Parcerias & & \\
\hline E39 & & & Ampliação da intervenção social \\
\hline
\end{tabular}

Fonte: Dados da pesquisa.

Sobre o entendimento de como as categorias "espaços e contextos de aprendizagem", "motivação para o empreendedorismo social" e "trajetória de liderança social" podem afetar o processo de formação do empreendedor social, é possível concluir que suas atitudes são construídas e renovadas continuamente, ao longo de sua história de vida. Não se trata, portanto, de uma formação realizada apenas em detrimento da atuação profissional e acadêmica, mas que exige, primordialmente, a atuação como cidadão, em um mundo que demanda pertencimento e reconstrução das relações sociais.

A essência da proposta de formação do empreendedor social deve, assim, basear-se na aprendizagem pela participação, isto é, os indivíduos aprendem pela colaboração em múltiplos espaços e contextos sociais (formal e informal), como salas de aula, laboratórios, núcleos de capacitação, incubadoras, mercado, comunidades locais, instituições, projetos sociais, associações e também junto ao núcleo familiar. À medida que aprendem participando, esses atores se tornam agentes pertencentes e interventores de uma realidade social colaborativa.

\section{Discussão}

Com base nos dados coletados, contatou-se que as 59 organizações, atuantes no Terceiro Setor e participantes do concurso, foram criadas e implantadas por empreendedores que geraram transformações sociais, reforçando os preceitos teóricos de Alvord, Brown e Letts (2004), Mair e Ignasi (2006), Austin, Stevenson e Wei-Skillern (2006) e Gohn (2015). O progresso das organizações mapeadas demandou a articulação de uma estrutura coletiva para geração de conhecimentos, experiências profissionais e de parcerias, que foram cruciais para as inovações sociais de impacto, corroborando as discussões de Certo e Miller (2008), Hoogendoorn, Pennings e Thurik (2010), Tondolo, Tondolo e Bitencourt (2013), Sloan, Legrand e Simons (2014).

Observou-se, ainda, que a formação dos empreendedores sociais assumiu um papel decisivo no que diz respeito à promoção e sustentação das organizações do Terceiro Setor analisadas, e também na geração efetiva das inovações sociais, reforçando as reflexões levantadas por Fleury e Fischer (2001), Bandura (2002), Friedlaender (2004), Murphy, Lião e Welsch (2006), pois o desenvolvimento desses indivíduos foi crucial para a determinação dos valores sociais coletivos criados, para a rede de parceiros estabelecida e para os procedimentos técnicos e interpessoais adotados pelos projetos sociais implementados, sendo agora atitudes replicadas em outras localidades, conforme evidenciaram as pesquisa de Farfus e Rocha (2007), Parente et al. (2011) e Sousa et al. (2013).

O processo de formação desses empreendedores sociais deve-se, por conseguinte, à trajetória de liderança social por eles construída, ou seja, o exercício pleno do empreendedorismo social, conforme enfatizado também por Yukl, Gordon e Taber (2002), Oliveira (2004) e David (2004). Também a um processo 
resultante dos espaços e contextos de aprendizagem aos quais eles foram submetidos ao longo da vida, além de suas motivações individuais de transformação social, o que confirma os achados de Minuzzi, Belinazo e Lezana (2005), Macêdo e Boava (2008), Navarro, Climent e Palacio (2011).

\section{Conclusão}

Os resultados demonstraram que a formação do empreendedor social está vinculada aos espaços e contextos de aprendizagem, à trajetória de liderança social e à motivação para o empreendedorismo social, sendo essas categorias permeadas pela educação formal e não formal.

Em relação à categoria "espaços e contextos de aprendizagem", nota-se a presença de uma formação definida como "formal", pois grande parte dos empreendedores analisados (51) são graduados. A importância desse fator se dá pela necessidade de o empreendedor adquirir habilidades e competências profissionais por meio de um processo educacional, considerando um conjunto de conhecimentos acadêmicos orientadores do seu trabalho como empreendedor. No entanto, apenas esse conhecimento formal não é suficiente para que uma pessoa ultrapasse o status de empreendedor, alcançando o de empreendedor social.

No contexto da categoria "trajetória de liderança social", constatou-se que o empreendedor social precisa, igualmente, de experiências vividas na coletividade, no "espaço não formal", experimentando o voluntariado e sentindo a vontade de fazer algo, a fim de atenuar e/ou sanar problemas sociais por meio de ações inovadoras. A liderança para o empreendedorismo social amplia o sentido de pertencimento e resulta em ações sociais que atendem às necessidades coletivas.

E, finalmente, em relação à categoria "motivação para o empreendedorismo social", o sentir-se motivado é o "combustível" que gera a energia suficiente para agir diante de uma situação-problema, identificada no âmbito social e da qual o empreendedor social se sente parte. Aprende-se com e na vida, experimentando situações e compartilhando-as com os outros. Nesse sentido, o empreendedor social, ao construir e consolidar sua identidade como agente de transformação, também dá sentido e passa a ser referência para a construção de uma identidade coletiva.

O indivíduo que pretende se inserir no universo do empreendedorismo social, necessariamente, precisa de experiências que só são adquiridas em contextos interativos, como nas organizações sociais, as quais promovem uma vivência de situações de cidadania e o senso de urgência em relação ao próximo, especialmente no espaço de formação não formal. Em síntese, os achados revelam a importância de se desenvolver atividades que despertem, na prática, o sentido do empreendedorismo social, envolvendo tanto a educação formal como a não formal.

Sabendo que o conhecimento sempre será um processo em construção, a proposta de "socialização empreendedora" e suas ações didáticas podem e devem ser objeto de novos estudos em prol da formação dos empreendedores sociais brasileiros.

Em relação às limitações da presente pesquisa, fica estabelecida a necessidade de olhá-la com a devida parcimônia, não sendo possível realizar generalizações acerca dos resultados obtidos, uma vez que eles estão explicitamente relacionados aos empreendedores sociais analisados. Além disso, há, ainda, a necessidade de triangulação entre as narrativas, obtidas em fontes secundárias, e dados obtidos de fontes primárias de evidência. Essa é uma proposta futura de estudo, a partir da realização de entrevistas aprofundadas e aplicação de questionários com/para empreendedores sociais brasileiros, a fim de complementar e ampliar as evidências secundárias já analisadas.

\section{Referências}

ABU-SAIFAN, S. Social entrepreneurship: definition and boundaries. Technology Innovation Management Review, [s. I.], v. 2, n. 2, p.22-27, Feb. 2012.

ADAM, J. M. A linguística textual: introdução à análise textual dos discursos. São Paulo: Cortez, 2008.

ALBERTI, V. Ouvir contar: textos em história oral. Rio de Janeiro: Editora FGV, 2004. 
ALVORD, S. H.; BROWN, L. D.; LETTS, C. W. Social entrepreneurship and societal transformation: an exploratory study. The Journal of Applied Behavioral Science, [s. I.], v. 40, n. 3, p. 260-282, Sep. 2004.

AUSTIN, J.; STEVENSON, H.; WEI-SKILLERN, J. Social and Commercial Entrepreneurship: Same, Different, or Both? Entrepreneurship Theory and Practice, [s. I.], v. 30, n. 1, p. 1-22, jan. 2006.

BANDURA, A. Social cognitive theory in cultural context. International Review, [s. I.], v. 51, n. 2, p. 269-290, Apr. 2002.

CERTO, S.; MILLER, T. Social entrepreneurship: Key issues and concepts. Business Horizons, [s. I.], v. 51, n. 4, p. 267- 271, Jul. 2008.

DACIN, M. T.; DACIN, P. A.; TRACEY, P. Social entrepreneurship: A critique and future directions.

Organization science, [s. I.], v. 22, n. 5, p. 1203-1213, Sep.-Oct. 2011.

DACIN, P. A.; DACIN, M. T.; MATEAR, M. Social entrepreneurship: Why we don't need a new theory and how we move forward from here. The academy of management perspectives, [s. I.], v. 24, n. 3, p. 37-57, 2010.

DAVID, D. E. H. Intra-empreendedorismo social: perspectivas para o desenvolvimento social nas organizações, 2004. Tese. (Doutorado em Engenharia de Produção) - Universidade Federal de Santa Catarina, Florianópolis, 2004.

DEES, J. G. et al. The Meaning of Social Entrepreneurship. Kansas City, MO and Palo Alto, CA: Kauffman Foundation and Stanford University, 1998. Disponpivel em: https://community-wealth.org/sites/clone. community-wealth.org/files/downloads/paper-dees.pdf. Acesso em: 23 jan. 2014.

DEES, J. G.; ECONOMY, P. Social entrepreneurship. In: DEES, J. G.; EMERSON, J.; ECONOMY, P. Enterprising Nonprofits: a toolkit for social entrepreneurs. New York: John Wiley \& Sons, 2001. p. 1-18.

DORNELAS, J. C. A. Empreendedorismo na prática: mitos e verdades do empreendedor de sucesso. Rio de Janeiro: Elsevier, 2007.

FARFUS, D.; ROCHA, M. C. de S. Inovação Social: um conceito em construção. In: FARFUS, D.; ROCHA, M. C. de S (org.). Inovações Sociais. Curitiba: SESI/SENAI/IEL/UNINDUS, p. 13-34, 2007. (Coleção Inova, v.2)

FLEURY, M. T. L.; FISCHER. R. M. Desenvolver competências e gerir conhecimento em diferentes arranjos empresariais: o caso da indústria brasileira de plásticos. In: FLEURY, M. T. L., \& OLIVEIRA JR., M. de M. (org.). Gestão estratégica do conhecimento: integrando aprendizagem, conhecimento e competências. São Paulo: Atlas, 2001.p. 189-211.

FREITAS, H.; JANISSEK, R. Análise léxica e análise de conteúdo: técnicas complementares, seqüenciais e recorrentes para exploração de dados qualitativos. Porto Alegre: Sagra Luzzatto, 2000.

FRIEDLAENDER, G. M. S. Metodologia de Ensino-Aprendizagem visando o Comportamento Empreendedor, 2004. Tese (Doutorado em Engenharia de produção) - Universidade Federal de Santa Catarina, Florianópolis, 2004.

GALVÃO, C. Narrativas em Educação. Ciência e Educação, Bauru, v. 11, n. 2, p. 327-345, May-Aug. 2005.

GATTI JR., D.; INÁCIO FILHO, G. História da educação em perspectiva: ensino, pesquisa, produção e novas investigações. Campinas (SP): Autores Associados, Uberlândia, MG: EDUFU, 2005. (Coleção memória da Educação).

GOHN, M. G. Educação não formal e o educador social: atuação no desenvolvimento de projetos sociais. $3^{\text {a }}$ ed. São Paulo: Cortez, 2013.

GOHN, M. G. Educação não formal no campo das Artes. São Paulo: Cortez, 2015.

GOHN, M. G. Educação não formal, participação da sociedade civil e estruturas colegiadas nas escolas.

Ensaio: aval. pol. públ. Educ., Rio de Janeiro, v.14, n.50, p. 27-38, jan./mar. 2006. 
HOOGENDOORN, B.; PENNINGS, E.; THURIK, R. What Do We Know About Social Entrepreneurship: An Analysis of Empirical Research. International Review of Entrepreneurship, [s.I.], v. 8, n. 2, p. 1-42, Jan. 2010.

INSTITUTO BRASILEIRO DE GEOGRAFIA E ESTATÍSTICA. Fundações privadas e associações sem fins lucrativos no Brasil. Disponível em: <www.ibge.gov.br>. Acesso em: 23 jan. 2014.

ITURRIOZ, C.; ARAGÓN, C.; NARVAIZA, L. How to foster shared innovation within SMEs' networks: Social capital and the role of intermediaries. European Management Journal, [s.I.], v. 33, n. 2, p. 104-115, 2015.

JACOBUCCI, D. F. C. Contribuições dos espaços não formais de educação para a formação da cultura científica. Uberlândia: Em Extensão. 2008.

JIAO, H. A conceptual model for social entrepreneurship directed toward social impact on society. Social Enterprise Journal, [s.I.], v. 7, n. 2, p. 130-149, 2011.

LEE, R. M.; ESTERHUIZEN, L. Computer software and qualitative analysis: Trends, issues, and responses. International Journal of Social Research Methodology, [s.I.], v. 3, p.231-243, 2000.

LIMA, M. C. Monografia: a engenharia da produção acadêmica. $2^{a}$ ed. São Paulo: Saraiva, 2008.

MACÊDO, F. M. F.; BOAVA, D. L. T. Relação empreendedor e reconhecimento social. In: SEMINÁRIOS EM ADMINISTRAÇÃO , 11., 2008, São Paulo. Anais [...] São Paulo: SEMEAD, 2008. p. 1-16.

MAIR, J.; IGNASI, M. Social entrepreneurship research: A source of explanation, prediction, and delight. Journal of world business, [s. I.], v. 41, n.1, p. 36-44, 2006.

MASSETO, M. T. Competência pedagógica do professor universitário. São Paulo: Summus, 2003. MELO NETO, F. P.; FRÓES. C. Empreendedorismo social: a transição para a sociedade sustentável. Rio de Janeiro: Qualitymark, 2002.

MELLO, A. M. G.; SANT'ANNA, A. S. Valores pessoais e organizacionais em diferentes grupamentos geracionais. Revista Ciências Administrativas, Fortaleza, v. 22, n. 1, p. 255-282, jan.-jun. 2016.

MINUZZI, J.; BELINAZO, D. P.; LEZANA, Á. G. R. As relações entre empreendedorismo e marketing social. As Relações entre Empreendedorismo e Marketing Social. In: SEMINÁRIO DE GESTÃO DE NEGÓCIOS, 2., 2005, Curitiba. Anais [...] Curitiba: [s. n.], 2015. p.1-16.

MUÑOZ, P.; KIBLER, E. Institutional complexity and social entrepreneurship: A fuzzy-set approach. Journal of Business Research, [s. I.], v. 69, n. 4, p. 1314-1318, 2016.

MURPHY, P. J.; LIAO, J.; WELSCH, H. P. A conceptual history of entrepreneurial thought. Journal of Management History, [s. I.], v. 12, n. 1, pp. 15-35, 2006.

NAVARRO, A. M.; CLIMENT, V. C.; PALACIO, J. R. S. Emprendimiento social y empresas de inserción en España. Aplicación del método delphi para la determinación del perfil del emprendedor y las empresas sociales creadas por emprendedores. Revesco, Belo Horizonte, v. 106, p. 150-172, Tercer Cuatrimestre, 2011.

NOSELLA, P.; AZEVEDO, M. L. N. A Educação em Gramsci. Revista Teoria e Prática da Educação, Maringá, v.15, n. 2, p. 25-33, 2012.

OLABUENAGA, J. I.; ISPIZUA, M. A. La descodificación de la vida cotidiana: métodos de investigación cualitativa. Espanha: Universidad de Deusto = Deustuko Unibertsitatea, 1989.

OLIVEIRA, E. M. Empreendedorismo social no Brasil: atual configuração, perspectivas e desafios notas introdutórias. Revista da FAE, Curitiba, v. 7, n. 2, p. 9-18, jul.-dez. 2004.

OLIVEIRA, I. B. Boaventura \& Educação. $2^{\mathrm{a}}$ ed., Belo Horizonte: Autêntica, 2008.

ONOZATO, E.; TEIXEIRA, R. M. Empreendedorismo social e a criação de organizações sociais: o estudo de 
caso do Instituto História Viva. Revista Ciências Administrativas, Fortaleza, v. 17, n. 2, p. 543-573, maioago. 2011.

PARENTE, C. et al. Empreendedorismo social: contributos teóricos para a sua definição. In: ENCONTRO NACIONAL DE SOCIOLOGIA INDUSTRIAL, DAS ORGANIZAÇÕES E DO TRABALHO EMPREGO E COESÃO SOCIAL: DA CRISE DA REGULAÇÃO À HEGEMONIA DA GLOBALIZAÇÃO, 14., 2011, Lisboa. Anais [...] Lisboa: , 2011, pp. 268-282.

PHILLIPS, W. et al. Social Innovation and Social Entrepreneurship A Systematic Review. Group \& Organization Management, [s. I.], v. 40, n. 3, p. 428-461, 2015.

RICHARDSON, R. J. Pesquisa Social: Métodos e Técnicas. Atlas: São Paulo, 1999.

ROMANELLI, G. O Significado da Educação Superior para duas gerações de famílias de camadas médias. Revista Brasileira de Estudos Pedagógicos, Brasília, v.6, n. 184, p. 445-476, 1995.

SLOAN, P.; LEGRAND, W.; SIMONS-KAUFMANN, C. A survey of social entrepreneurial community-based hospitality and tourism initiatives in developing economies. A new business approach for industry. Worldwide Hospitality and Tourism Themes, [s.I.], v. 6, n. 1, p. 51-61, 2014.

SOUSA, E. G.; BUENO, J. M.; SOUSA, M. G.; TECH, L. O Perfil do Empreendedor Social e Suas Dimensões de Atuação: Um Estudo de Seis Casos no Município de Uberlândia-MG. In: ENCONTRO DA ANPAD, 37. 2013, Rio de Janeiro. Anais [...]. Rio de Janeiro: ENANPAD, 2013. p.1-16.

TONDOLO, R. R. P.; TONDOLO, V. A. G.; BITENCOURT, C. C. Correlação entre Elementos do Capital Social e Orientação Empreendedora: um estudo exploratório. Revista Eletrônica de Ciência Administrativa, Campo Largo, v. 12, n. 1, p. 92-105, 2013.

WILLEMS, J. Individual perceptions on the participant and societal functionality of non-formal education for youth: explaining differences across countries based on the human development index. International Journal of Educational Development, [s. I.], v. 44 (C), p. 11-20, 2015. DOI: 10.1016/j.ijedudev.2015.07.003

YUKL, G.; GORDON, A.; TABER, T. A hierarchical taxonomy of leadership behavior: integrating a half century of behavior research. Journal of Leadership Organizational Studies, [s. I.], v. 9, n. 1, p. 15-32, 2002.

Submetido em: $17 / 09 / 2017$

Aprovado em: 04/02/2019 